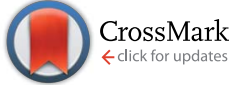

Cite this: J. Mater. Chem. A, 2016, 4, 6940

Received 18th September 2015 Accepted 26th November 2015

DOI: $10.1039 / c 5 t a 07511 d$

www.rsc.org/MaterialsA

\section{Bisisoindigo: using a ring-fusion approach to extend the conjugation length of isoindigo $\uparrow$}

\begin{abstract}
Nicholas M. Randell, Philip C. Boutin and Timothy L. Kelly*
The synthesis of bisisoindigo, a near IR absorbing electron acceptor in which two isoindigo units are ringfused along the 6 and 7 positions, is reported. An electron-deficient bisisatin was first synthesized using the Martinet isatin synthesis, after which two concurrent aldol condensations with 1-alkyl-2-oxindole yielded the ring-fused isoindigo dimer. The ring fusion significantly extends the conjugation length of the molecule relative to the isoindigo parent compound. The bisisoindigo sub-unit was then coupled to 2,2'-bithiophene, yielding a new organic semiconductor with a donor-acceptor structure. Both bisisoindigo and the donor-acceptor compound absorb light well into the near IR; the donor-acceptor compound features an absorption edge of almost $1000 \mathrm{~nm}$ in the solid state. Both compounds were employed in prototype organic photovoltaic devices alongside common electron donors and acceptors.
\end{abstract}

\section{Introduction}

In the last several years, there have been significant advances in the field of organic semiconductor design that have produced substantial increases in the efficiency of organic photovoltaic (OPV) devices and the performance of organic field effect transistors (OFETs). One of the chief reasons behind these advances has been the rise of new organic semiconductors characterized by their use of alternating electron donor and acceptor units. ${ }^{1}$ Juxtaposition of these units leads to materials with substantially reduced band gaps and good charge carrier mobilities. Common electron donors are often thiophene based (e.g., benzodithiophene, ${ }^{2,3}$ thieno[3,2- $\left.b\right]$ thiophene $\left.{ }^{4-6}\right)$, due to the electron-rich nature of the thiophene ring. In contrast, electronwithdrawing imide and amide groups are prevalent in common acceptor units such as diketopyrollopyrrole and isoindigo.

Isoindigo was first incorporated into organic semiconductors by Mei et al., ${ }^{7}$ and has since become ubiquitous throughout the field of organic electronics as an electron accepting unit in both polymers and small molecules. ${ }^{8-15}$ Many studies have varied the identity of donor groups and alkyl chains, but relatively few variations of isoindigo itself have been reported. ${ }^{16-21}$ Among the few reported modifications to isoindigo are the 7-haloisoindigos (both chloro and fluoro derivatives), ${ }^{16,17,22}$ and thienoisoindigo, where the benzene ring is replaced with thiophene. ${ }^{\mathbf{1 8 - 2 0}}$ In recent work, the conjugation length of thienoisoindigo has been extended by the fusion of

Department of Chemistry, University of Saskatchewan, 110 Science Pl., Saskatoon, SK, S7N 5C9, Canada. E-mail: tim.kelly@usask.ca; Fax: +1-306-966-4730; Tel: +1-306966-4666

$\dagger$ Electronic supplementary information including detailed synthetic procedures, photovoltaic characterization, fluorescence quenching, atomic force microscopy and NMR spectra available online. See DOI: 10.1039/c5ta07511d additional aromatic rings to the molecular structure. Both thienothiophene and benzothienothiophene have been used in this fashion to extend the planarity and conjugation length of isoindigos in organic electronics. ${ }^{23,24}$

More recently, the concept of using crossed aldol reactions to form expanded isoindigo units has been reported. The reaction of an isatin with benzodifurandione has been shown to produce an expanded, lactone-containing isoindigo system, ${ }^{25,26}$ and the same type of crossed aldol reaction between benzodifurandione and a thienoisatin yields the thienoisoindigo analogue. ${ }^{27} \mathrm{~A}$ second example of an expanded isoindigo system is prepared from the condensation of 2,2'-bithiophene-5,5'-dicarboxaldehyde with an isatin to form an isoindigo-like motif containing an interior bithiophene group. ${ }^{28}$ Most recently, two groups independently synthesized an expanded isoindigo structure in which one phenyl ring bears two lactam moieties oriented para- to one another. ${ }^{29,30}$ Our work has been inspired by the idea of exploiting crossed aldol chemistry to expand the isoindigo core unit, as well as using ring fusion to further extend the conjugation length of the system.

Herein, we report the synthesis of bisisoindigo, an expanded isoindigo structure that consists of two isoindigo moieties fused across the 6 and 7 positions. The bisisoindigo building block features a highly extended conjugation length, having an optical band gap well into the near infrared. The dibromobisisoindigo derivative was coupled to a 2,2'-bithiophene moiety to create an organic semiconductor with a donor-acceptor motif. Thin films of this material absorb across the entire visible region, with an absorption edge of nearly $1000 \mathrm{~nm}$. Both bisisoindigo and the donor-acceptor compound were incorporated into the active layers of OPVs. While device performance was modest, both bisisoindigo-based compounds were able to function as electron donors. Bisisoindigo is an exciting new electron-deficient 
building block in the synthesis of organic semiconductors, and it is anticipated that through judicious choice of both donor sub-unit and alkyl chain length, it will lead to a number of new, high-performance organic semiconductors.

\section{Experimental}

\section{Materials and characterization}

Prior to use DMF and toluene were dried over activated $3 \AA$ molecular sieves and stored under $\mathrm{N}_{2} \cdot \mathrm{Pd}\left(\mathrm{PPh}_{3}\right)_{4}$ was stored in an inert atmosphere $\mathrm{N}_{2}$ glove box when not in use. All other solvents and reagents were used as received. NMR spectra were obtained using a Bruker Avance $500 \mathrm{MHz}$ spectrometer. UV/vis spectroscopy measurements were performed in $\mathrm{CHCl}_{3}$ or as thin films on glass substrates using a Cary $6000 \mathrm{UV} / \mathrm{vis}$ spectrophotometer. AFM measurements were performed using a Dimensions Hybrid Nanoscope system (Veeco Metrology Group). Cyclic voltammetry was carried out in $0.05 \mathrm{~mol} \mathrm{~L}^{-1}$ tetrabutylammonium hexafluorophosphate dissolved in dry, degassed $\mathrm{CH}_{2} \mathrm{Cl}_{2}$. The working electrode was glassy carbon, the counter electrode was a Pt wire, and the reference electrode was a Ag wire. Voltammograms were referenced to an internal $\mathrm{Fc} / \mathrm{Fc}^{+}$ standard. Mass spectra were acquired on a JEOL AccuToF 4G GCv mass spectrometer with an EiFi field desorption ionization source. Melting points were measured using a DigiMelt MPA160 (Stanford Research Systems) melting point analyser. Elemental analysis was carried out on a $2400 \mathrm{CHN}$ Elemental analyser (Perkin Elmer).

Synthesis of bisisatin (2). 1,5-Diaminonaphthalene (2.01 g, $12.7 \mathrm{mmol}$ ) was dissolved in $20 \mathrm{~mL}$ of glacial acetic acid and heated to reflux. To the resulting purple solution was added a solution of diethylketomalonate $(8.0 \mathrm{~mL}, 52 \mathrm{mmol})$ in glacial acetic acid $(23 \mathrm{~mL})$ dropwise over 0.75 hours. The resulting redbrown suspension was heated at reflux for 18 hours. The acetic acid was removed in vacuo and the resulting red solid was dissolved in $1 \mathrm{~mol} \mathrm{~L}^{-1} \mathrm{NaOH}$ to a final solution $\mathrm{pH}$ of between 11 and 12. The resulting dark brown solution was heated at reflux with sparging air for 5 hours. The solution was then poured onto ice and acidified to $\mathrm{pH} 0$ with aqueous $6 \mathrm{~mol} \mathrm{~L}^{-1} \mathrm{HCl}$. The resulting red-purple solid was collected by suction filtration, washed with $\mathrm{H}_{2} \mathrm{O}$ and dried in vacuo to yield the crude product as a black-purple solid $(3.28 \mathrm{~g}, 97 \%)$. The crude product was determined to be approximately $75 \%$ pure by ${ }^{1} \mathrm{H}$ NMR spectroscopy; however, due to its extremely low solubility, the product was carried forward without further purification. ${ }^{1} \mathrm{H}$ NMR (500 MHz, DMSO- $\left.d_{6}, \delta\right): 11.78(\mathrm{~s}, 2 \mathrm{H}), 7.79(\mathrm{~d}, J=8.3 \mathrm{~Hz}$, $2 \mathrm{H}), 7.61(\mathrm{~d}, J=8.3 \mathrm{~Hz}, 2 \mathrm{H})$.

Synthesis of $N, N^{\prime}$-bis(2-ethylhexyl)bisisatin (3). In an oven dried Schlenk flask, crude $2(2.42 \mathrm{~g}, 9.08 \mathrm{mmol})$ and freshly dried $\mathrm{K}_{2} \mathrm{CO}_{3}(3.16 \mathrm{~g}, 22.9 \mathrm{mmol})$ were dissolved in $50 \mathrm{~mL}$ of dry DMF. The reaction mixture was heated to $70{ }^{\circ} \mathrm{C}$, 2-ethylhexyliodide $(8.60 \mathrm{~g}, 35.8 \mathrm{mmol})$ was added via syringe, and the temperature was increased to $100^{\circ} \mathrm{C}$ for a further 5.5 hours. The reaction mixture was poured over $200 \mathrm{~mL} \mathrm{H}_{2} \mathrm{O}$ and acidified to pH 7 with aqueous $1 \mathrm{~mol} \mathrm{~L}^{-1} \mathrm{HCl}$. The aqueous layer was extracted with $\mathrm{CH}_{2} \mathrm{Cl}_{2}$. The organic layers were dried over $\mathrm{MgSO}_{4}$ and concentrated to yield the crude product as a viscous black oil. The crude product was purified by column chromatography on silica gel (eluent: $1: 3$ EtOAc : hexanes) followed by recrystallization from 1:3 EtOAc : hexanes. The resulting blue solid was isolated by suction filtration and dried in vacuo. Total yield 3: $984 \mathrm{mg}$ (30\% yield, assuming $75 \%$ pure 1). $\mathrm{Mp} 175{ }^{\circ} \mathrm{C}$ (decomp.). ${ }^{1} \mathrm{H}$ NMR (500 MHz, $\mathrm{CDCl}_{3}, \delta$ ): 8.00 (d, $J=8.7 \mathrm{~Hz}$, $2 \mathrm{H}), 7.67(\mathrm{~d}, J=8.6 \mathrm{~Hz}, 2 \mathrm{H}), 4.11-4.24(\mathrm{~m}, 5 \mathrm{H}), 1.85-1.91(\mathrm{~m}$, $2 \mathrm{H}), 1.23-1.45(\mathrm{~m}, 16 \mathrm{H}), 0.93(\mathrm{t}, J=7.5 \mathrm{~Hz}, 6 \mathrm{H}), 0.87(\mathrm{t}, J=6.6$ $\mathrm{Hz}, 6 \mathrm{H}) .{ }^{13} \mathrm{C}$ NMR $\left(125 \mathrm{MHz}, \mathrm{CDCl}_{3}, \delta\right): 182.7,159.3,152.3$, 127.4, 120.1, 120.0, 116.4, 47.2, 38.7, 30.1, 28.4, 28.3, 23.5, 23.0, 14.0, 10.35, 10.33. HRMS $(\mathrm{m} / \mathrm{z}):\left(\mathrm{M}^{\cdot+}\right)$ calc. $\left(\mathrm{C}_{30} \mathrm{H}_{38} \mathrm{~N}_{2} \mathrm{O}_{4}\right)$ : 490.28316 found: 490.28261. Anal. calcd for $\mathrm{C}_{30} \mathrm{H}_{38} \mathrm{~N}_{2} \mathrm{O}_{4}$ : C, 73.44; H, 7.81; N, 5.71; found: C, 73.43; H, 7.70; N, 5.64.

Synthesis of bisisoindigo (6). Compounds $3(399 \mathrm{mg}, 0.812$ $\mathrm{mmol}$ ) and 4 ( $478 \mathrm{mg}, 1.95 \mathrm{mmol})$ were dissolved in $15 \mathrm{~mL}$ of glacial acetic acid. Concentrated $\mathrm{HCl}(100 \mu \mathrm{L})$ was added and the reaction mixture was heated at reflux for 14 hours. After 14 hours the reaction mixture was poured over a mixture of ice and brine, and extracted with $\mathrm{CH}_{2} \mathrm{Cl}_{2}$. The combined organic layers were washed with brine, dried over $\mathrm{MgSO}_{4}$, and concentrated to yield the crude product as a black solid. The crude product was purified by column chromatography (silica gel, eluent: $60: 40 \mathrm{CH}_{2} \mathrm{Cl}_{2}$ : hexanes) and concentrated in vacuo to yield a dark brown-black solid (347 mg, 45\%). Mp 250-252 ${ }^{\circ} \mathrm{C}$. ${ }^{1} \mathrm{H}$ NMR $\left(500 \mathrm{MHz}, \mathrm{CD}_{2} \mathrm{Cl}_{2}, \delta\right): 9.06(\mathrm{~d}, J=7.9 \mathrm{~Hz}, 2 \mathrm{H}), 9.00(\mathrm{~d}$, $J=9.3 \mathrm{~Hz}, 2 \mathrm{H}), 7.87(\mathrm{~d}, J=9.36,2 \mathrm{H}), 7.37(\mathrm{t}, J=8.2,2 \mathrm{H}), 7.03(\mathrm{t}$, $J=7.4 \mathrm{~Hz}, 2 \mathrm{H}), 6.82(\mathrm{~d}, J=7.8 \mathrm{~Hz}), 4.20-4.35(\mathrm{~m}, 4 \mathrm{H}), 3.62-3.73$ $(\mathrm{m}, 4 \mathrm{H}), 1.98-2.07(\mathrm{~m}, 2 \mathrm{H}), 1.84-1.92(\mathrm{~m}, 2 \mathrm{H}), 1.22-1.48(\mathrm{~m}$, 37H), 0.84-0.99 (m, 26H). ${ }^{13} \mathrm{C}$ NMR (125 MHz, $\left.\mathrm{CDCl}_{3}, \delta\right): 169.9$, 168.1, 145.4, 143.2, 134.0, 132.9, 132.4, 129.2, 124.3, 123.4, 122.3, 122.1, 120.1, 117.2, 108.4, 47.0, 44.3, 38.5, 37.7, 30.8, 30.2, $28.8,28.3,24.1,23.5,23.1,14.1,14.0,10.7,10.5$. HRMS $(\mathrm{m} / \mathrm{z})$ : $\left(\mathrm{M}^{++}\right)$calc. $\left(\mathrm{C}_{62} \mathrm{H}_{80} \mathrm{~N}_{4} \mathrm{O}_{4}\right)$ : 944.61795 found: 944.62061. Anal. calcd for $\mathrm{C}_{62} \mathrm{H}_{80} \mathrm{~N}_{4} \mathrm{O}_{4}: \mathrm{C}, 78.77 ; \mathrm{H}, 8.53 ; \mathrm{N}, 5.93$; found: C, 77.79; $\mathrm{H}, 8.60 ; \mathrm{N}, 5.78$.

Synthesis of dibromo-bisisoindigo (7). Compound 3 (462.6 $\mathrm{mg}, 0.9433 \mathrm{mmol})$ and $5(827.6 \mathrm{mg}, 2.55 \mathrm{mmol})$ were dissolved in $20 \mathrm{~mL}$ of glacial acetic acid. Concentrated $\mathrm{HCl}(100 \mu \mathrm{L})$ was added and the reaction mixture was heated at reflux for 18 hours. The reaction mixture was poured over $\mathrm{H}_{2} \mathrm{O}$ and extracted with $\mathrm{CH}_{2} \mathrm{Cl}_{2}$. The combined organic layers were washed with brine, dried over $\mathrm{MgSO}_{4}$, and concentrated to yield the crude product. The crude product was purified by column chromatography (silica gel, eluent: $70: 30 \mathrm{CH}_{2} \mathrm{Cl}_{2}$ : hexanes, gradient to $10: 1 \mathrm{CH}_{2} \mathrm{Cl}_{2}: \mathrm{MeOH}$ ), concentrated in vacuo to yield a brownblack solid, and washed with acetone (235 mg, 23\%). Mp 237$252{ }^{\circ} \mathrm{C}$ (decomp.). ${ }^{1} \mathrm{H}$ NMR $\left(500 \mathrm{MHz}, \mathrm{CDCl}_{3}, \delta\right): 8.95$ (dd, $J_{1}=$ $\left.2.4 \mathrm{~Hz}, J_{2}=9.0 \mathrm{~Hz}, 4 \mathrm{H}\right), 7.84(\mathrm{~d}, J=9.4 \mathrm{~Hz}, 2 \mathrm{H}), 7.17(\mathrm{~d}, J=8.6$ $\mathrm{Hz}, 2 \mathrm{H}), 6.90(\mathrm{~s}, 2 \mathrm{H}), 4.18-4.30(\mathrm{~m}, 4 \mathrm{H}), 3.58-3.71(\mathrm{~m}, 4 \mathrm{H}), 1.95-$ $2.04(\mathrm{~m}, 2 \mathrm{H}), 1.80-1.90(\mathrm{~m}, 2 \mathrm{H}), 1.21-1.47(\mathrm{~m}, 34 \mathrm{H}), 0.83-0.98$ (m, 25H). ${ }^{13} \mathrm{C}$ NMR $\left(125 \mathrm{MHz}, \mathrm{CDCl}_{3}, \delta\right): 169.9,168.0,143.4$, 132.6, 132.6, 130.3, 126.9, 125.2, 120.8, 117.3, 111.7, 47.0, 44.4, 38.5, 37.5, 30.6, 30.2, 28.6, 28.3, 24.0, 23.5, 23.1, 14.1, 14.0, 10.7, 10.5, 7.8. HRMS $(\mathrm{m} / \mathrm{z})\left(\mathbf{M}^{+}\right)$calc. $\left(\mathrm{C}_{62} \mathrm{H}_{78} \mathrm{Br}_{2} \mathrm{~N}_{2} \mathrm{O}_{4}\right): 1102.43693$ found: 1102.43715. Anal. calcd for $\mathrm{C}_{62} \mathrm{H}_{78} \mathrm{Br}_{2} \mathrm{~N}_{2} \mathrm{O}_{4}: \mathrm{C}, 67.51 ; \mathrm{H}$, 7.13; N, 5.08; found: C, 67.15; H, 7.45; N, 5.91. 
Synthesis of bis-bithiophene-bisisoindigo (8). Compound 7 (145 mg, $0.132 \mathrm{mmol}), \operatorname{Pd}\left(\mathrm{PPh}_{3}\right)_{4}(11.1 \mathrm{mg}, 9.6 \mu \mathrm{mol})$, and 5'-hexyl-5-tributylstannyl-2,2'-bithiophene $\quad(315 \mathrm{mg}, \quad 0.584$ mmol) were added sequentially to $15 \mathrm{~mL}$ dry, degassed toluene. The reaction mixture was heated to reflux for 15 hours. The reaction mixture was concentrated in vacuo, purified by column chromatography (silica gel, eluent $70: 30$ toluene : hexanes, gradient to $3 \%$ methanol : toluene), and the product recrystallized from $\mathrm{CH}_{2} \mathrm{Cl}_{2} /$ acetone to yield a blue-black solid $(151 \mathrm{mg}$, 80\%). Mp 237-245 ${ }^{\circ} \mathrm{C} .{ }^{1} \mathrm{H}$ NMR (500 MHz, $\mathrm{CD}_{2} \mathrm{Cl}_{2}, \delta$ ): 9.02 (d, $J=$ $8.4 \mathrm{~Hz}, 2 \mathrm{H}), 8.90(\mathrm{~d}, J=9.2 \mathrm{~Hz}, 2 \mathrm{H}), 7.78(\mathrm{~d}, J=9.6 \mathrm{~Hz}, 2 \mathrm{H}), 7.31$ $(\mathrm{d}, J=3.8 \mathrm{~Hz}, 2 \mathrm{H}), 7.21(\mathrm{~d}, J=8.7 \mathrm{~Hz}, 2 \mathrm{H}) 7.05(\mathrm{q}, J=5.8 \mathrm{~Hz}$, $4 \mathrm{H}), 6.71(\mathrm{~d}, J=3.6 \mathrm{~Hz}), 4.19-4.34(\mathrm{~m}, 5 \mathrm{H}), 3.60-3.78(\mathrm{~m}, 5 \mathrm{H})$, $2.80(\mathrm{t}, J=7.6 \mathrm{~Hz}, 3 \mathrm{H}), 1.97-2.04(\mathrm{~m}, 3 \mathrm{H}), 1.82-1.91(\mathrm{~m}, 2 \mathrm{H})$, 1.65-1.73 (m, 4H), 1.53-1.63 (m, 6H), 1.21-1.49 (m, 39H), 0.82$1.00(\mathrm{~m}, 24 \mathrm{H}) .{ }^{13} \mathrm{C} \mathrm{NMR}\left(125 \mathrm{MHz}, \mathrm{CDCl}_{3}, \delta\right): 169.8,168.3,146.2$, $145.8,142.6,141.8,138.9,137.8,134.5,132.5,130.6,129.9$, $125.2,125.0,124.1,124.0,123.8,122.9,121.1,119.9,118.5$, 117.0, 104.5, 46.9, 44.0, 38.5, 37.8, 31.6, 31.56, 30.9, 30.3, 30.2, $29.7,28.0,28.8,28.8,28.4,28.3,24.2,23.5,23.2,23.2,23.1,22.6$, 14.2, 14.1, 10.9, 10.6, 10.6, 10.5. HRMS $(\mathrm{m} / \mathrm{z})\left(\mathbf{M}^{\cdot+}\right)$ calc. $\left(\mathrm{C}_{90} \mathrm{H}_{112} \mathrm{~N}_{4} \mathrm{O}_{4} \mathrm{~S}_{4}\right): 1440.75664$ found: 1440.75420 . Anal. calcd for $\mathrm{C}_{90} \mathrm{H}_{112} \mathrm{~N}_{4} \mathrm{O}_{4} \mathrm{~S}_{4}$ : C, 74.96; $\mathrm{H}, 7.83$; N, 3.88; found: $\mathrm{C}, 74.78 ; \mathrm{H}$, 8.49; N, 3.29.

\section{Results and discussion}

\section{Synthesis}

The preparation of bisisoindigo (Scheme 1) presented several distinct synthetic challenges. Isatins are often synthesized by the Sandmeyer isatin synthesis. ${ }^{31}$ Attempts to perform the Sandmeyer isatin synthesis using 1,5-diaminonaphthalene (1) as described by Kossmehl and Manecke ${ }^{32}$ yielded the desired bisisatin (2) as a minor product and aminobenzoisatin as the major product (Scheme S1 ESI†). The ring-closing step of the Sandmeyer isatin synthesis requires the electrophilic aromatic substitution of a hydroxyimine group onto a benzene ring. ${ }^{33}$ When attempting to perform this reaction twice on a single ring system, the formation of the first isatin withdraws much of the electron density from the ring, preventing the second ring closure. Therefore, in order to synthesize bisisatin (2), the Martinet isatin synthesis (Scheme S1 ESI $\dagger$ ) was employed. ${ }^{34}$ In this reaction, the ring closing step produces a 3-hydroxy-2oxindole intermediate. This group is much less electron withdrawing than an isatin, and therefore the aromatic ring is not deactivated towards the second ring closure. Bubbling air is sufficient to oxidize both 3-hydroxy-2-oxindole groups to the corresponding isatins, producing 2 as the major product. The electron deficient nature of 2 stabilizes the anion formed by deprotonation of the amide, making it a poor nucleophile, and alkyl iodides were required to alkylate the heterocyclic $\mathrm{N}$-atom to form 3. An acid-catalysed double crossed aldol reaction of 3 and the appropriate 2-oxindole derivatives (4 or 5 ) was then used to complete the synthesis of $\mathbf{6}$ and 7. The dibrominated derivative was subsequently used in a Stille cross-coupling reaction with 5-tributylstannyl-5'-hexyl-2,2'-bithiophene to form a donor-acceptor-donor molecule, 8. Significant colour changes were noted with each subsequent extension of the conjugation; $\mathbf{3}$ is a blue solid, $\mathbf{6}$ is a brown-black solid, and $\mathbf{8}$ is a dark blue-black solid.

\section{Energy levels and absorption spectra of 6 and 8}

Solution and solid state UV/vis spectroscopy was performed on 6 and 8 (Fig. 2a and b). Using time dependent density functional theory (TDDFT) calculations (Fig. 1 and 2c), the lowest energy peak in the spectra of both 6 and $\mathbf{8}$ can be assigned to the HOMOto-LUMO transition; the additional peak at $625 \mathrm{~nm}$ in the spectrum of $\mathbf{8}$ is assigned to a transition from a bithiophenebased $\pi$-orbital to the LUMO. As a result of the extended conjugation in bisisoindigo, both molecules absorb well into the near infrared. The effect of the donor bithiophene group is immediately apparent when the spectra of $\mathbf{6}$ and $\mathbf{8}$ are compared. While the HOMO-to-LUMO transition in $\mathbf{6}$ has a relatively low oscillator strength, the HOMO-to-LUMO transition in $\mathbf{8}$ is much more intense. This increase in oscillator strength is also predicted by the TDDFT calculations. Calculation of the frontier orbital geometries of both 6 and 8 (Fig. 1) reveals a higher degree of orbital localization in the LUMO of the donor-acceptor compound. While both the HOMO and LUMO of 6 are delocalized across the entire molecule, the LUMO of $\mathbf{8}$ is isolated almost entirely on the bisisoindigo core. This localization leads to an increase in the transition dipole moment of the HOMO-toLUMO transition, greatly increasing its extinction coefficient. The large extinction coefficient and small band gap (Table 1) of 8 are ideal characteristics for application in organic photovoltaic devices. Cyclic voltammetry (Fig. 2d) was used to determine the absolute energy levels of 6 and 8 (Table 1). Consistent with the addition of electron donating bithiophene groups, the HOMO of 8 lies $0.2 \mathrm{eV}$ higher in energy than that of $\mathbf{6}$; however, the energy of the LUMO is unchanged, providing further evidence that the bithiophene groups do not appreciably contribute to the LUMO. Compound 6 exhibits a quasi-reversible oxidation wave, as well as two independent quasi-reversible reduction peaks. Conversely, neither the oxidation nor reduction of $\mathbf{8}$ was reversible. Upon oxidation and reduction a solid film was noted on the surface of the glassy carbon electrode. The onset of oxidation and reduction were used to estimate the HOMO and LUMO levels of $\mathbf{6}$ and $\mathbf{8}$, and are listed in Table 1.

\section{Performance in OPV devices}

The cyclic voltammetry results indicated that the frontier orbital energies of both 6 and $\mathbf{8}$ lay in between those of OPV donor materials such as PTB7-Th, ${ }^{3}$ and fullerene-based acceptors such as phenyl- $\mathrm{C}_{71}$-butyric acid methyl ester $\left(\mathrm{PC}_{71} \mathrm{BM}\right)$. This suggested that 6 and 8 could be used as either the electron donor or the electron acceptor in an OPV device. Therefore, $\mathbf{6}$ and $\mathbf{8}$ were tested in both roles: as the electron acceptor (blended with PTB7$\mathrm{Th}$ ), and as the electron donor (blended with $\mathrm{PC}_{71} \mathrm{BM}$ ). OPVs were first fabricated using an active layer blend of PTB7-Th:6 (Table 2, Fig. S1 and S2 ESI †). Device performance was modest, but improved greatly with the addition of 1,8-diiodooctane (DIO). Atomic force microscopy (AFM) images of PTB7-Th:6 blends (Fig. S3 ESI $\dagger$ ) suggests that the addition of DIO decreases 
<smiles>[Z]OC(=O)C(=O)C(=O)OCC</smiles><smiles>[X]c1ccc2c(c1)N([R])C(=O)C2</smiles>

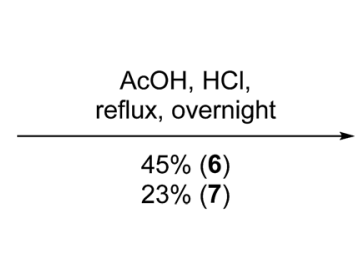

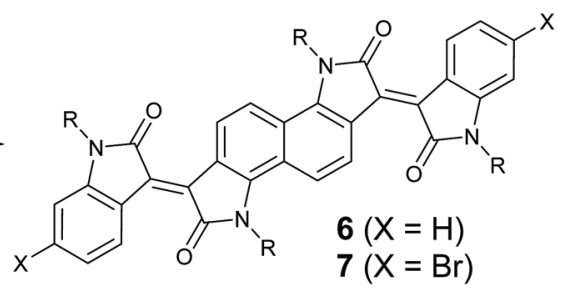<smiles></smiles><smiles>[R]c1ccc(-c2ccc(OCCC)s2)s1</smiles>

$\mathrm{Pd}\left(\mathrm{PPh}_{3}\right)_{4}$, toluene, reflux, overnight $78 \%$<smiles>[R]c1ccc(-c2ccc(/C=C/C)s2)s1</smiles>

Scheme 1 Synthesis of bisisoindigo (6) and bis(5'-hexyl-2,2'-bithienyl)-bisisoindigo (8).

the domain size from $\sim 1 \mu \mathrm{m}$ to $<100 \mathrm{~nm}$. Unfortunately, even upon addition of DIO, some large crystallites were still visible. However, although the overall efficiency was low, the devices did nonetheless display very high $V_{\text {oc }}$ values (up to $1.0 \mathrm{~V}$ ). OPVs fabricated with PTB7-Th:8 active layers also performed relatively poorly. This is likely because $\mathbf{8}$ was insufficiently soluble in chlorobenzene and $o$-dichlorobenzene, the ideal solvents for processing PTB7-Th. The films cast from chloroform exhibited poor film morphologies and large domain sizes, which greatly reduced device performance (Fig. S1 and S4 ESI $\dagger$ ).
Although poor film morphology is likely the cause of the poor photovoltaic performance, one alternative is a lack of energetic driving force for electron transfer at the donor/acceptor interface. Electron transfer between the donor (PTB7-Th) and acceptor (6/8) was therefore evaluated using solution phase fluorescence spectroscopy (Fig. S6-S8 ESI $\dagger$ ); a decrease in donor fluorescence in the presence of $\mathbf{6}$ or $\mathbf{8}$ is indicative of electron transfer. In order to extract quantitative information regarding fluorescence quenching, a Stern-Volmer analysis was performed (Fig. S8 ESI $\dagger$ ). The fluorescence quenching of PTB7-Th yielded

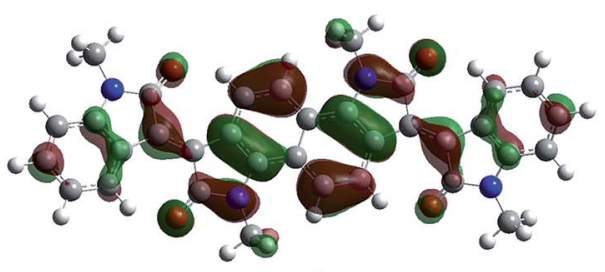

6

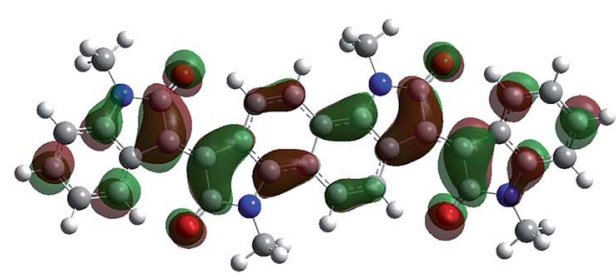

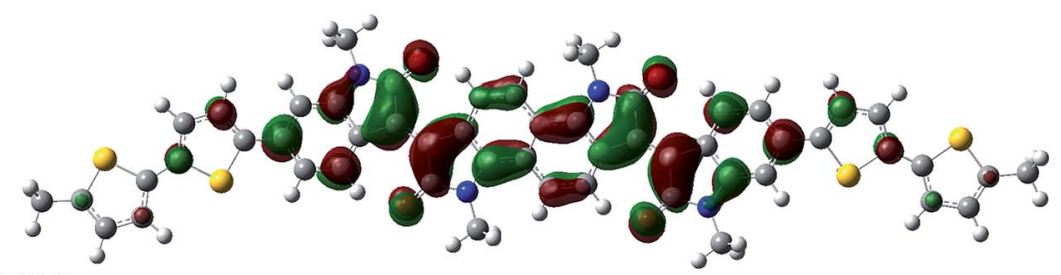

LUMO

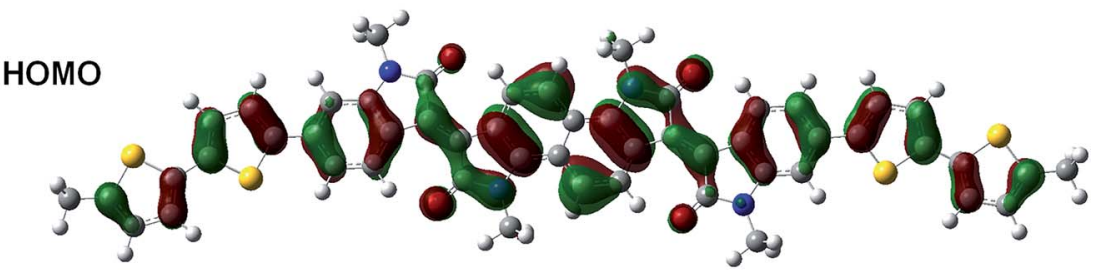

Fig. 1 Frontier molecular orbitals of 6 and 8. 

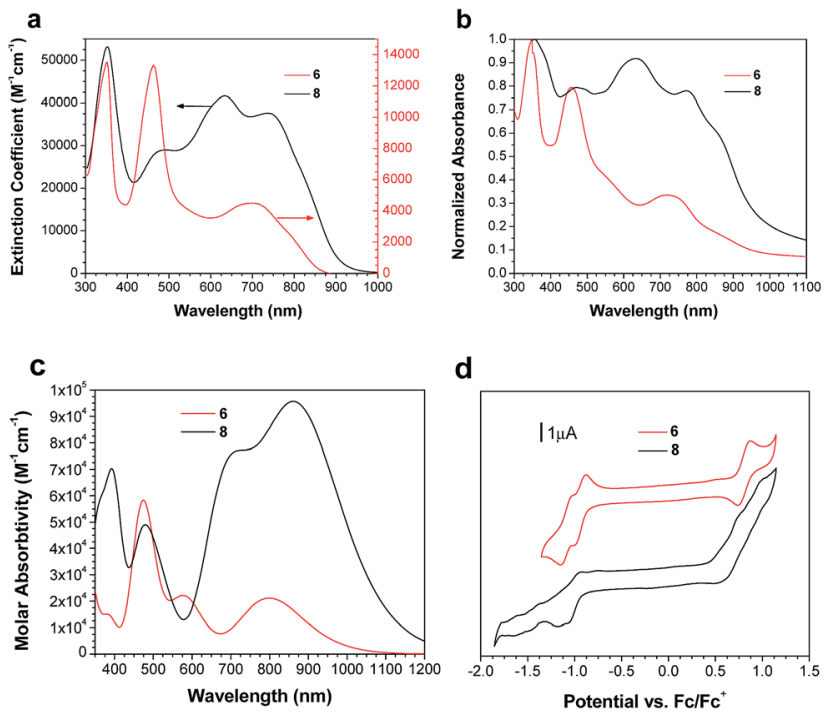

Fig. $2 \mathrm{UV} / \mathrm{vis}$ absorption spectra of 6 and 8 in (a) $\mathrm{CHCl}_{3}$ and (b) as a thin film on glass. (c) theoretical UV/vis spectra of 6 and 8 . (d) Cyclic voltammograms of 6 and 8 in $0.05 \mathrm{~mol} \mathrm{~L}^{-1}\left(\mathrm{NBu}_{4}\right) \mathrm{PF}_{6}$ in $\mathrm{CH}_{2} \mathrm{Cl}_{2}$.

Stern-Volmer constants of $(6 \pm 1) \times 10^{4} \mathrm{~mol}^{-1}$ L when quenched by 6 , and $(1.1 \pm 0.2) \times 10^{4} \mathrm{~mol}^{-1} \mathrm{~L}$ when quenched by 8 (Table S5 ESI $\dagger$ ). These values are similar to the Stern-Volmer quenching constant obtained when $\mathrm{P} 3 \mathrm{HT}$ emission is quenched by $\mathrm{PC}_{61} \mathrm{BM}$ $\left(1.6 \times 10^{4} \mathrm{~mol}^{-1} \mathrm{~L}\right) .^{35}$ This suggests that there is a sufficiently large energy level offset to split the exciton at the donor/acceptor interface, and that either the morphology or the electron mobility limit the performance of these devices.

Both 6 and 8 were then evaluated as electron donors alongside $\mathrm{PC}_{71} \mathrm{BM}$ (Table 2, Fig. 3). DIO loadings between $0 \%$ and $3 \%$ were investigated (see $\mathrm{ESI}_{\dagger} \dagger$ ) and the champion device using 6: $\mathrm{PC}_{71} \mathrm{BM}$ and $1 \%$ DIO produced an efficiency of $0.28 \%$. The current densities produced by these cells were $3 \times$ greater than those of the PTB7-Th containing cells. Similarly, devices with an active layer of $8: \mathrm{PC}_{71} \mathrm{BM}$ performed much better than the analogous PTB7-Th:8 devices. However, these devices suffered from a much lower fill factor than those using 6: $\mathrm{PC}_{71} \mathrm{BM}$ active layers (Fig. 3a). This is likely due to the poor blend morphology, which again results from the use of chloroform as the casting solvent. Optical microscopy revealed cracks in the 8: $\mathrm{PC}_{71} \mathrm{BM}$ films, which would be expected to lead to microshorts and carrier recombination, decreasing the fill factor. The larger

Table 1 Calculated and experimental frontier orbital energy levels and band gaps of 6 and 8

\begin{tabular}{llllll}
\hline Compound & $\begin{array}{l}E_{\mathrm{HOMO}}{ }^{a} \\
(\mathrm{eV})\end{array}$ & $\begin{array}{l}E_{\mathrm{LUMO}}{ }^{b} \\
(\mathrm{eV})\end{array}$ & $\begin{array}{l}E_{\mathrm{Gap}}{ }^{c} \\
(\mathrm{eV})\end{array}$ & $\begin{array}{l}E_{\mathrm{Gap}}{ }^{d} \\
(\mathrm{eV})\end{array}$ & $\begin{array}{l}E_{\mathrm{Gap}}{ }^{e} \\
(\mathrm{eV})\end{array}$ \\
\hline 6 & 5.8 & 4.2 & 1.6 & 1.55 & 1.44 \\
8 & 5.6 & 4.2 & 1.4 & 1.42 & 1.27
\end{tabular}

${ }^{a}$ From onset of oxidation, $\mathrm{Fc} / \mathrm{Fc}^{+}$referenced as $5.1 \mathrm{eV}$ relative to vacuum. ${ }^{b}$ From onset of reduction. ${ }^{c} E_{\text {HOMO }}-E_{\text {LUMO }}$, as determined from voltammograms. ${ }^{d}$ Calculated from TDDFT results (see ESI $\dagger$ ). ${ }^{e}$ Calculated from the absorption onset.
Table 2 Champion photovoltaic device performance of ITO/ PEDOT:PSS/active layer/LiF/Al bulk heterojunction solar cells

\begin{tabular}{|c|c|c|c|c|}
\hline Active layer & $\begin{array}{l}V_{\mathrm{oc}} \\
(\mathrm{V})\end{array}$ & $\begin{array}{l}J_{\mathrm{sc}} \\
\left(\mathrm{mA} \mathrm{cm}^{-2}\right)\end{array}$ & $\begin{array}{l}\text { Fill factor } \\
(\%)\end{array}$ & $\begin{array}{l}\text { Efficiency } \\
(\%)\end{array}$ \\
\hline PTB7-Th:6 & 1.0 & 0.33 & 31 & 0.10 \\
\hline $6: \mathrm{PC}_{71} \mathrm{BM}$ & 0.68 & 0.92 & 45 & 0.28 \\
\hline PTB7-Th:8 & 0.60 & 0.030 & 27 & 0.0048 \\
\hline 8: $\mathrm{PC}_{71} \mathrm{BM}$ & 0.59 & 1.28 & 30 & 0.23 \\
\hline
\end{tabular}
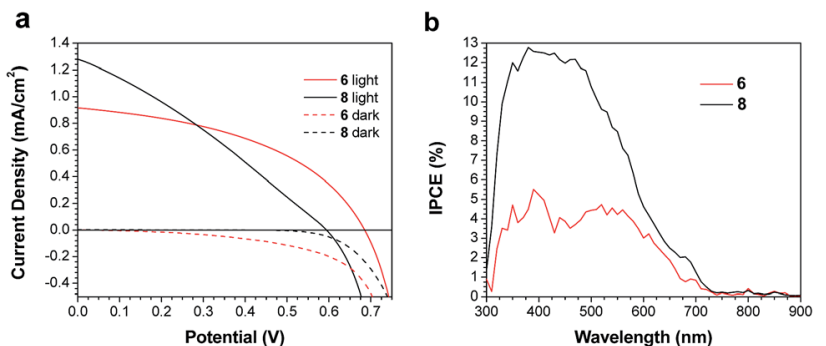

Fig. 3 (a) J-V curves for champion devices, and (b) IPCE spectra for devices based on active layers of 6 or 8 and $\mathrm{PC}_{71} \mathrm{BM}$.
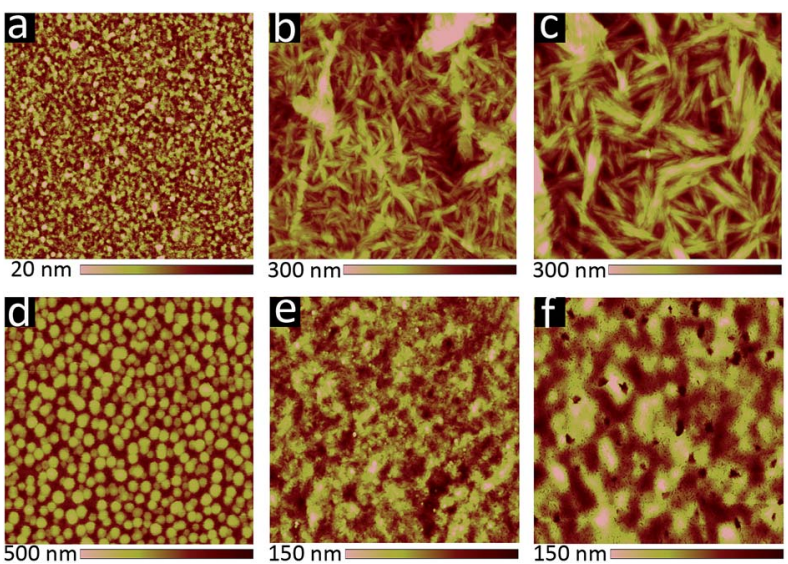

Fig. $410 \times 10 \mu \mathrm{m}$ AFM images of active layer blends cast from $20 \mathrm{mg}$ $\mathrm{mL}^{-1}$ solutions; (a-c) 6:PC $\mathrm{C}_{71} \mathrm{BM}$ active layers with (a) $0 \%$, (b) $1 \%$, (c) $3 \%$ $\mathrm{DIO}(\mathrm{v} / \mathrm{v})$; (d-f) 8: $\mathrm{PC}_{71} \mathrm{BM}$ active layers with (d) $0 \%$, (e) $1 \%$, (f) $3 \% \mathrm{DIO}$ (v/v).

extinction coefficient of 8 relative to 6 is reflected in a higher incident photon-to-current efficiency (IPCE) (Fig. 3b). As in the PTB7-Th based OPVs, the addition of DIO was required to optimize the performance of the 6/8: $\mathrm{PC}_{71} \mathrm{BM}$ devices; however, instead of seeing a decrease in domain size, the formation of larger domains is observed (Fig. 4). The addition of $1 \%$ DIO to 6: $\mathrm{PC}_{71} \mathrm{BM}$ blends greatly increased the device performance, while a $3 \%$ loading led to domains that were too large, leading to a decrease in device efficiency.

\section{Conclusions}

In conclusion, we have reported the synthesis of a unique electron acceptor sub-unit incorporating two isoindigo units 
fused along the 6 and 7 positions (6). This acceptor sub-unit was then coupled to 2,2'-bithiophene donor groups to form a donoracceptor compound (8). Both $\mathbf{6}$ and $\mathbf{8}$ absorb light well into the near infrared, with 8 exhibiting a large extinction coefficient due to a higher degree of intramolecular charge transfer character in the HOMO-to-LUMO transition. 6 and 8 were incorporated into OPV active layers (paired with either PTB7-Th or $\mathrm{PC}_{71} \mathrm{BM}$ ). Although the power conversion efficiencies were modest, bisisoindigo (6) features the deep energy levels desired in an electron acceptor, and $\mathbf{8}$ absorbs strongly throughout the visible and into the near infrared, demonstrating the utility of the bisisoindigo building block. The incorporation of 6 into new donor-acceptor compounds (both polymers and small molecules) may therefore yield a variety of new, high-performance organic semiconductors.

\section{Acknowledgements}

The Natural Science and Engineering Research Council of Canada (NSERC) and the University of Saskatchewan are acknowledged for financial support. T. L. K. is a Canada Research Chair in Photovoltaics. This research was undertaken in part, thanks to funding from the Canada Research Chairs Program. N. M. R. and P. C. B. thank NSERC for scholarship funding; P. C. B. also thanks the Government of Saskatchewan for the Queen Elizabeth II Centennial Aboriginal Scholarship.

\section{Notes and references}

1 A. J. Heeger, Chem. Soc. Rev., 2010, 39, 2354-2371.

2 C. Y. Mei, L. Liang, F. G. Zhao, J. T. Wang, L. F. Yu, Y. X. Li and W. S. Li, Macromolecules, 2013, 46, 7920-7931.

3 S. H. Liao, H. J. Jhuo, Y. S. Cheng and S. A. Chen, Adv. Mater., 2013, 25, 4766-4771.

4 I. McCulloch, M. Heeney, M. L. Chabinyc, D. DeLongchamp, R. J. Kline, M. Cölle, W. Duffy, D. Fischer, D. Gundlach, B. Hamadani, R. Hamilton, L. Richter, A. Salleo, M. Shkunov, D. Sparrowe, S. Tierney and W. Zhang, Adv. Mater., 2009, 21, 1091-1109.

5 J. C. Bijleveld, R. A. M. Verstrijden, M. M. Wienk and R. A. J. Janssen, J. Mater. Chem., 2011, 21, 9224-9231.

6 J. A. Schneider, H. Black, H. P. Lin and D. F. Perepichka, ChemPhysChem, 2015, 16, 1173-1178.

7 J. Mei, K. R. Graham, R. Stalder and J. R. Reynolds, Org. Lett., 2010, 12, 660-663.

8 E. Wang, W. Mammo and M. R. Andersson, Adv. Mater., 2014, 26, 1801-1826.

9 R. Stalder, J. Mei, K. R. Graham, L. A. Estrada and J. R. Reynolds, Chem. Mater., 2013, 26, 664-678.

10 C. C. Ho, C. A. Chen, C. Y. Chang, S. B. Darling and W. F. Su, J. Mater. Chem. A, 2014, 2, 8026-8032.

11 Z. Wang, J. Zhao, Y. Li and Q. Peng, Polym. Chem., 2014, 5, 4984-4992.

12 E. D. Głowacki, G. Voss and N. S. Sariciftci, Adv. Mater., 2013, 25, 6783-6800.
13 X. Guo, A. Facchetti and T. J. Marks, Chem. Rev., 2014, 114, 8943-9021.

14 R. Stalder, J. Mei, J. Subbiah, C. Grand, L. A. Estrada, F. So and J. R. Reynolds, Macromolecules, 2011, 44, 6303-6310.

15 F. Grenier, P. Berrouard, J. R. Pouliot, H. R. Tseng, A. J. Heeger and M. Leclerc, Polym. Chem., 2013, 4, 18361841.

16 T. Lei, J. H. Dou, Z. J. Ma, C. H. Yao, C. J. Liu, J. Y. Wang and J. Pei, J. Am. Chem. Soc., 2012, 134, 20025-20028.

17 T. Lei, J. H. Dou, Z. J. Ma, C. J. Liu, J. Y. Wang and J. Pei, Chem. Sci., 2013, 4, 2447-2452.

18 Y. Koizumi, M. Ide, A. Saeki, C. Vijayakumar, B. Balan, M. Kawamoto and S. Seki, Polym. Chem., 2013, 4, 484-494.

19 G. K. Dutta, A. R. Han, J. Lee, Y. Kim, J. H. Oh and C. Yang, Adv. Funct. Mater., 2013, 23, 5317-5325.

20 G. Kim, S. J. Kang, G. K. Dutta, Y. K. Han, T. J. Shin, Y. Y. Noh and C. Yang, J. Am. Chem. Soc., 2014, 136, 9477-9483.

21 N. M. Randell, A. F. Douglas and T. L. Kelly, J. Mater. Chem. A, 2014, 2, 1085-1092.

22 Y. Deng, J. Liu, J. Wang, L. Liu, W. Li, H. Tian, X. Zhang, Z. Xie, Y. Geng and F. Wang, Adv. Mater., 2014, 26, 471-476.

23 I. Meager, M. Nikolka, B. C. Schroeder, C. B. Nielsen, M. Planells, H. Bronstein, J. W. Rumer, D. I. James, R. S. Ashraf, A. Sadhanala, P. Hayoz, J. C. Flores, H. Sirringhaus and I. McCulloch, Adv. Funct. Mater., 2014, 24, 7109-7115.

24 W. Yue, R. S. Ashraf, C. B. Nielsen, E. Collado-Fregoso, M. R. Niazi, S. A. Yousaf, M. Kirkus, H. Y. Chen, A. Amassian, J. R. Durrant and I. McCulloch, Adv. Mater., 2015, 27, 4702-4707.

25 T. Lei, J. H. Dou, X. Y. Cao, J. Y. Wang and J. Pei, Adv. Mater., 2013, 25, 6589-6593.

26 X. Zhou, N. Ai, Z. H. Guo, F. D. Zhuang, Y. S. Jiang, J. Y. Wang and J. Pei, Chem. Mater., 2015, 27, 1815-1820.

27 G. Zhang, Z. Ye, P. Li, J. Guo, Q. Wang, L. Tang, H. Lu and L. Qiu, Polym. Chem., 2015, 6, 3970-3978.

28 S. Li, Z. Yuan, J. Yuan, P. Deng, Q. Zhang and B. Sun, J. Mater. Chem. A, 2014, 2, 5427-5433.

29 J. Pei, Y. Cao, J. S. Yuan, X. Zhou, X. Y. Wang, F. D. Zhuang and J. Y. Wang, Chem. Commun., 2015, 51, 10514-10516.

30 Y. He, C. Guo, B. Sun, J. Quinn and Y. Li, Chem. Commun., 2015, 51, 8093-8096.

31 J. F. D. Silva, S. J. Garden and A. C. Pinto, J. Braz. Chem. Soc., 2001, 12, 273-324.

32 G. Kossmehl and G. Manecke, Makromol. Chem., 1975, 176, 333-340.

33 B. V. Silva, F. A. Violante, A. C. Pinto and L. S. Santos, Rapid Commun. Mass Spectrom., 2011, 25, 423-428.

34 K. C. Rice, B. J. Boone, A. B. Rubin and T. J. Rauls, J. Med. Chem., 1976, 19, 887-892.

35 W. Senevirathna and G. Sauvé, J. Mater. Chem. C, 2013, 1, 6684-6694. 